\title{
Recent advances in understanding/management of hypospadias
}

\section{Warren Snodgrass* and Nicol Bush}

Address: University of Texas Southwestern Medical Center and Children's Medical Center, 1935 Medical District Drive, Dallas, TX 75235, USA

*Corresponding author: Warren Snodgrass (warren.snodgrass@childrens.com)

FI000Prime Reports 2014, 6:10I (doi:10.12703/P6-101)

All Fl000Prime Reports articles are distributed under the terms of the Creative Commons Attribution-Non Commercial License (http://creativecommons.org/licenses/by-nc/3.0/legalcode), which permits non-commercial use, distribution, and reproduction in any medium, provided the original work is properly cited.

The electronic version of this article is the complete one and can be found at: http://fl 000 .com/prime/reports/m/6/10 I

\begin{abstract}
Hypospadias is the second most common birth anomaly, affecting I of every 300 males. The abnormal position of the urinary opening, and associated downward curvature of the penis in some cases, potentially impact both urinary and sexual function. Modern surgical correction most often involves tubularization of the urethral plate, those tissues which normally should have completed urethral development.

This article discusses recent progress in hypospadias repair. Prospective data collection in consecutive patients promotes better understanding of both patient and technical factors that influence surgical complications. Patients with a proximal urinary opening near or within the scrotum, those failing prior to repairs, and/or those with a small glans diameter have increased likelihood for urethroplasty complications. Quality review of reliable data led to two layer urethroplasty covered with tunica vaginalis in proximal repairs, significantly reducing postoperative fistulas. Neither preoperative androgens used to grow a small diameter glans, nor a change in sutures used to approximate the glans wings reduced wound dehiscence, but a recent technical modification of the glansplasty with more extensive dissection before suturing has. The observation that reoperation increases risk for further complications three-fold suggests the less common proximal repairs and reoperations should be subspecialized so that designated surgeons can gain greater expertise.

In addition, surgeons performing hypospadias repair must better define the complications that occur so that scientific reporting of outcomes becomes more standardized. Standardized objective means to assess results are also needed so that surgeons performing different repairs can compare outcomes.
\end{abstract}

\section{Introduction}

Hypospadias is the second most common birth defect, occurring in 1:300 males. Most have a distal urethral opening on or near the glans, whereas in $10 \%$ the meatus is located between the proximal shaft and the perineum (Figure 1). The condition is usually diagnosed in newborns, recognized by the incompletely developed dorsal foreskin. Ventral curvature occurs in 10\% of distal and $80 \%$ of proximal cases, and bending of greater than $30^{\circ}-$ the extent that causes adult sexual dysfunction-is found in over half of the latter patients (Figure 2) [1]. Uncorrected hypospadias can result in a deflected or spraying urinary stream as well as impaired sexual activity. Furthermore, the abnormal appearance of the foreskin and glans can be a source of embarrassment to affected males.
Surgical repair began in the late 1890s, and over the ensuing years many techniques have been described to extend the urethra to the normal terminus. The initial focus was on proximal hypospadias, which causes the most morbidity but is also the most difficult to correct. The modern era dates to the meatal advancement and glanduloplasty (MAGPI) procedure described in the early 1980s [2], which made distal repair routine.

Subsequently, midline tissues distal to the meatus were recognized as those that should have completed urethral development and labelled the urethral plate. Today, tubularization of the urethral plate, usually after dorsal incision to widen it [3], is the most common means used to correct distal hypospadias and is also an option to 
Figure I. The phenotype of hypospadias
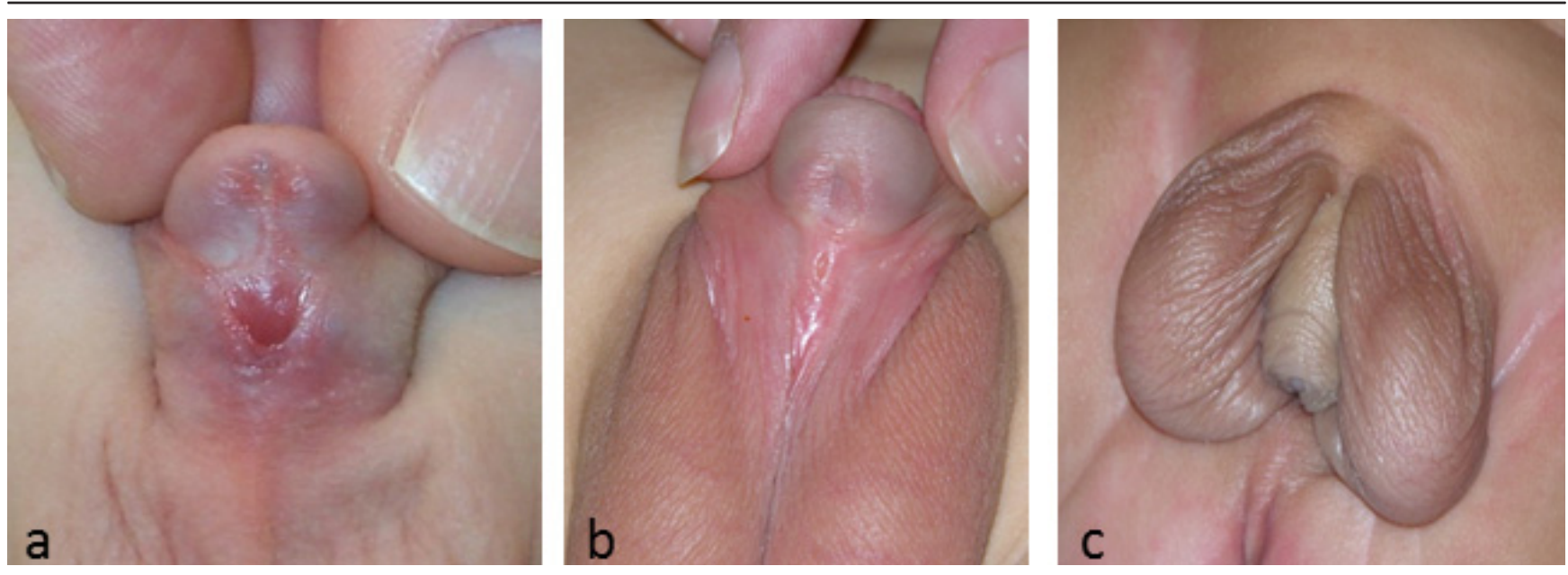

(a) Distal. (b) Scrotal. (c) Perineal.

Figure 2. Proximal hypospadias with ventral curvature of more than $30^{\circ}$ after release of the penile shaft skin

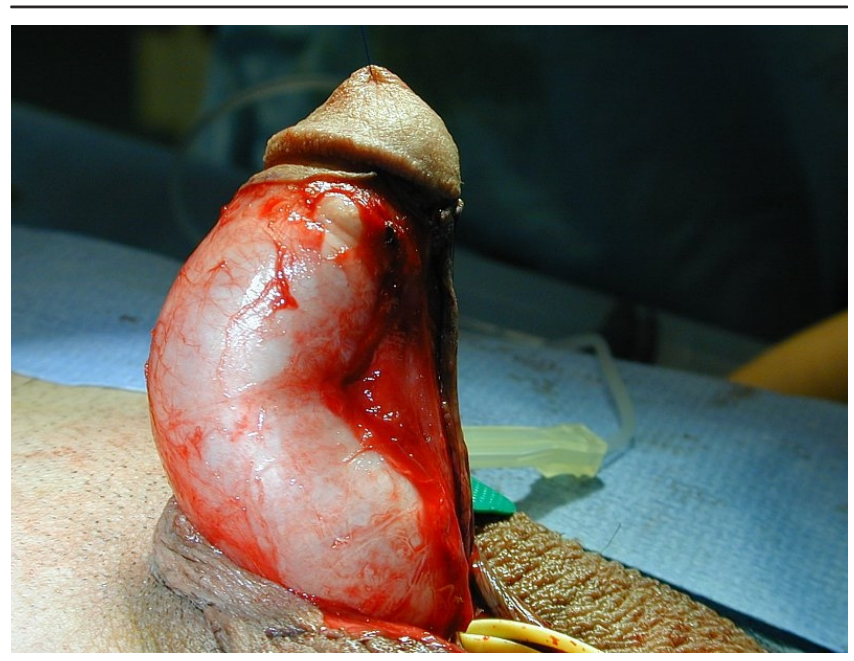

repair proximal cases that have either no curvature or bending of less than $30^{\circ}$. The best procedure for proximal repair with greater than $30^{\circ}$ curvature has not been determined.

With urethral plate tubularization (tubularized incised plate urethroplasty repair, or TIP repair) has come increased reliance on fewer surgical techniques for both primary and reoperative repairs. A reduced algorithm enables surgeons to gain greater expertise with each procedure, facilitates learning for trainees, and allows hypospadiologists to discover factors other than the operative technique that influence outcomes.
This review examines recent progress in primary hypospadias surgery as well as means for future improvements. Processes we examine and experiences we relate can also be used to improve outcomes from other surgical procedures.

\section{Prospective data collection}

Warren Snodgrass created a descriptive database in Excel (Microsoft Corporation) and began recording predetermined data points on the day of service to capture intraoperative and postoperative findings in every patient with hypospadias he treated beginning in 1999, a quality initiative that is the source of our observations. In 2009, Nicol Bush reconfigured that database to enable easier statistical analyses and started her own outcomes database. Finally, in 2013, our fellow Melise Keays collaborated with information technology services at our hospital to create electronic data input sheets (Epic). Now individual and group operative experience and outcomes can be determined and tracked electronically.

These databases were established for quality monitoring and improvement, but with institutional review board approval they have also been reviewed for academic reporting. As new questions arose, additional columns were added, making the databases responsive instruments supplementing both our clinical practice and academic activities. Today, we have prospectively collected data in over 2,000 consecutive hypospadias operations.

Others have created databases from review of patient charts. Although such retrospective collections have some merit, disadvantages of chart reviews include missing data and inconsistent descriptions of findings. Furthermore, 
we have observed that systematic data input helped to standardize both our operative procedures, since we are frequently reminded of the sutures and suturing methods, and our measurements, since we had to agree at the onset exactly how to do them! Otherwise, there is a tendency to be less regimented when performing operations, especially those such as proximal hypospadias repairs done relatively infrequently, and this potentially introduces confounders when trying to understand factors impacting outcomes.

\section{Non-technical factors influencing outcomes}

Although the goal of hypospadias repair is a normalappearing and normal-functioning penis, the outcome measure most often reported is the rate of urethroplasty complications (UCs). It has long been observed that proximal hypospadias repair and reoperations have higher UCs than do distal repairs. Our data in 669 boys with TIP urethroplasty confirmed those impressions, as UCs occurred three times more often after reoperations and nearly two times more frequently when the meatus was midshaft or more proximal [4]. However, the analysis by Nicol Bush added the unique observation that glans size is also an independent predictor for UCs. Glans diameter, measured at the widest point $(\leq 14 \mathrm{~mm})$, confers a 2.7-fold greater risk for UCs, and each millimeter increase reduces that risk [5]. Although most patients with a small glans have proximal hypospadias, some with a distal meatus also measure $\leq 14 \mathrm{~mm}$, and, as discussed below, glansplasty modification applied to these cases reduces UCs. Consequently, we now begin each repair determining the glans diameter (Figure 3).

Our data analyses also identify factors that do not directly influence UCs. For example, speculation that increasing

Figure 3. Measuring maximum glans width

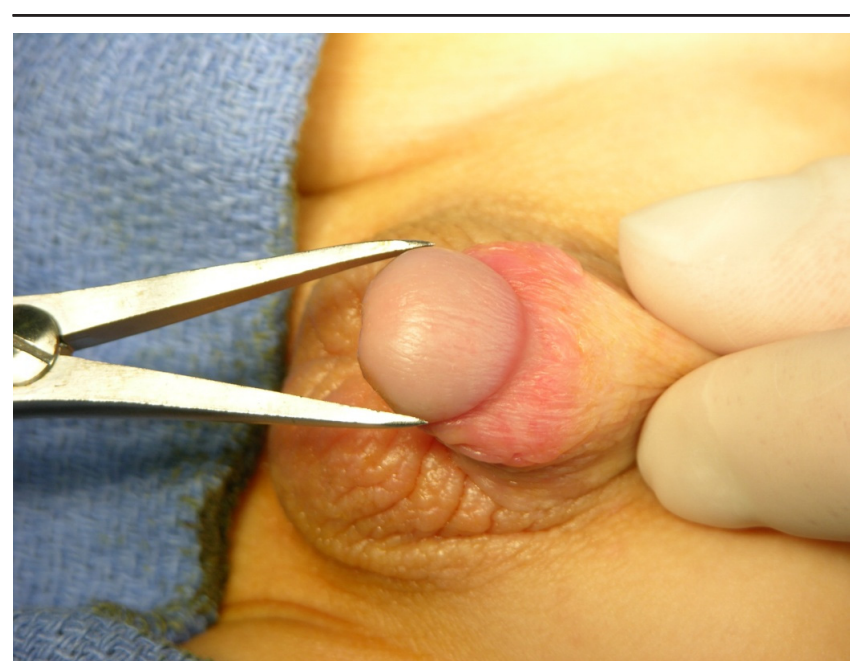

age at repair increases UCs was not borne out by our experience either in prepubertal boys of varying ages [4] or when prepubertal cases were compared with those done in teens and adults with at least Tanner 4 development [6]. Therefore, repair can be done at any age with the same expectations for UCs, and adults can be reconstructed with the same goals of a normal-functioning and normalappearing penis that we strive for in children.

\section{Defining urethroplasty complications}

Although UCs are the endpoint of most studies, the various possible complications have not been clearly defined so that surgeons can diagnose and then report them similarly. While fistulas are easily recognized, they most often occur subcoronally below either a well-healed glans or a short band of skin bridging separated glans wings (Figure 4). The distinction is important, as simple fistula closure can be done under well-approximated glans wings, whereas reoperative hypospadias repair is needed when the glans repair is dehisced [7]. Accordingly, those in the first group should be reported as fistulas whereas the latter are more accurately defined as glans dehiscences-or at least as fistulas combined with dehiscence.

Similarly, there are no established criteria to diagnose meatal stenosis, and we have given second opinions regarding the need for meatotomy when openings simply appear small in asymptomatic patients. Accordingly, we recommend that stenosis be defined by stranguria with meatal calibration of less than $8 \mathrm{Fr}$ in prepubertal boys or $14 \mathrm{Fr}$ in adults.

Our most common UC is glans dehiscence, defined as separation of the glans wings that most often results in a subcoronal meatus. It includes patients who complain of spraying from a glanular meatus formed by a ventral band of skin bridging separated wings, which is also dehiscence (Figure 5). We found that this complication occurred 3.6 times more often after proximal versus distal TIP repair, although the same surgeon used the same sutures and suturing methods [8]. That observation led us to speculate that the size of the glans might account for the different outcomes.

\section{Lessons learned from glans dehiscence}

To test this hypothesis, we next agreed that the most reproducible objective measure of glans size would be its diameter at the widest point, recognizing that there are also varying shapes that might influence surgical outcomes but are much more difficult to quantify. Then we systematically recorded the width in patients with distal and proximal hypospadias as well as in newborns undergoing elective circumcision. We found that the mean glans width was a significantly smaller $12.9 \mathrm{~mm}$ in 
Figure 4. Subcoronal fistulas

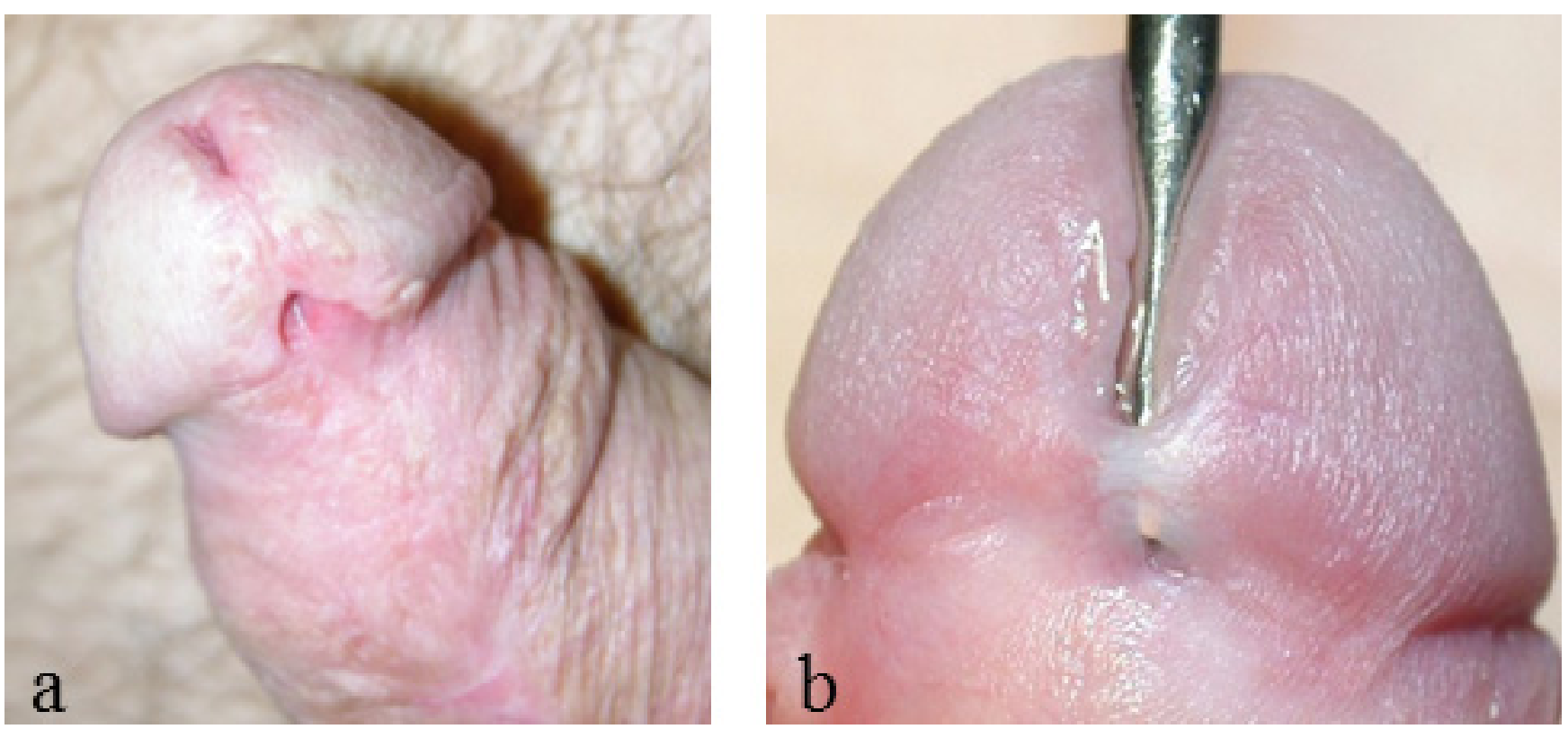

(a) Fistula with a well-healed glans allowing simple fistula closure. (b) Fistula resulting from glans dehiscence beneath a thin band of skin between the glans.

\section{Figure 5. Glans dehiscence}

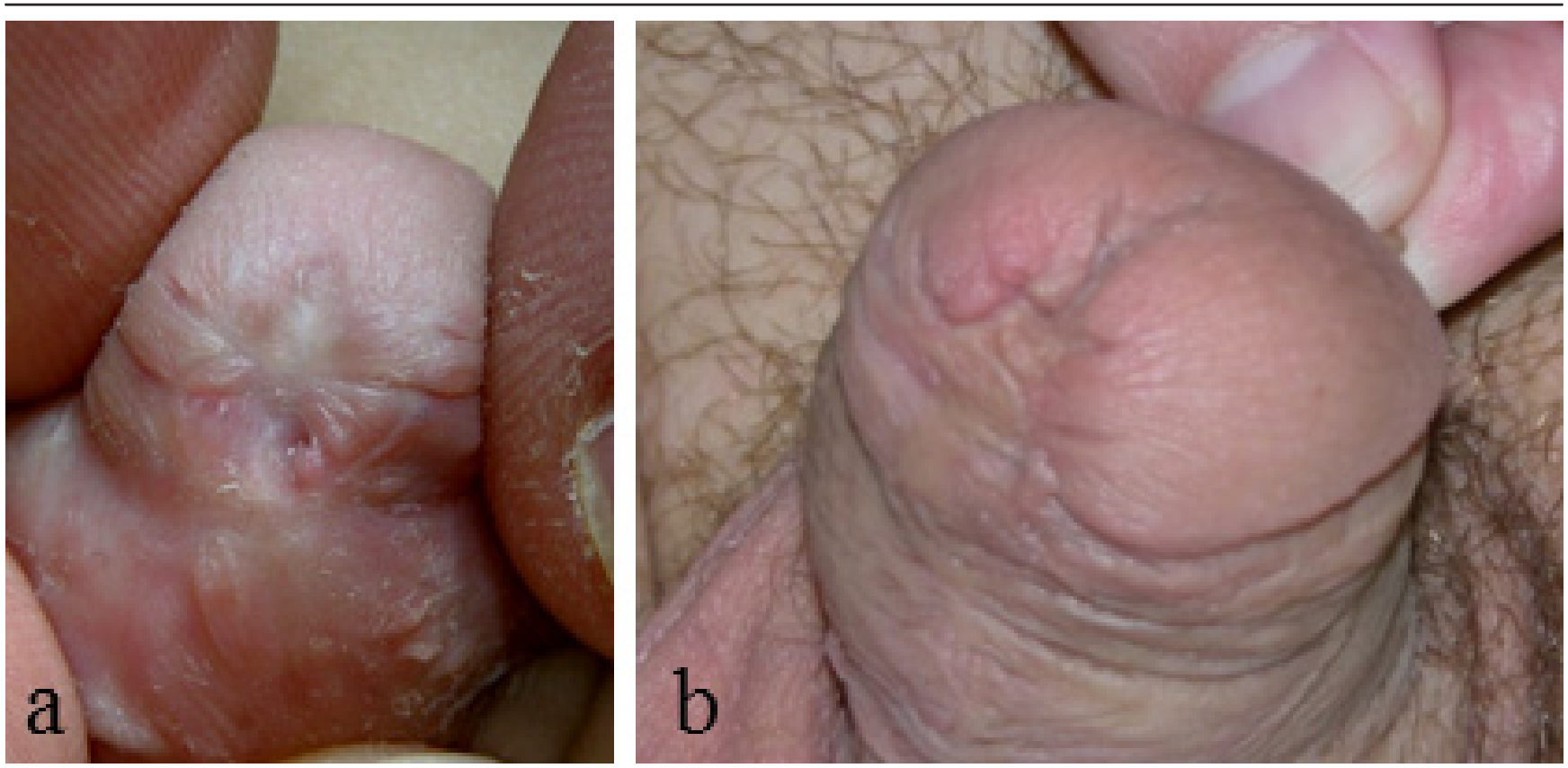

(a) Complete separation of the glans wings with a subcoronal meatus. (b) Pseudoglandular meatus created by skin bridge across separated glans wings, resulting in urinary spraying. 
patients with proximal hypospadias measured at an average age of 9 months than the $14.8 \mathrm{~mm}$ in similaraged boys with distal hypospadias or $14.3 \mathrm{~mm}$ in normal newborns [9].

\section{Preoperative androgens}

Knowing that preoperative androgen stimulation increases glans circumference [10-12], we then began intramuscular injections of $2 \mathrm{mg} / \mathrm{kg}$ testosterone in patients whose glans measured $\leq 14 \mathrm{~mm}$, with the goal of growing it to at least $15 \mathrm{~mm}$, the average size in boys with distal hypospadias in which glans dehiscence is much less common. This was the first reported objective study with defined inclusion criteria and endpoints for adjuvant hormonal treatment [13]. We observed that the recommended two or three preoperative injections of $2 \mathrm{mg} / \mathrm{kg}$ failed to increase glans width sufficiently in over half the proximal patients, whereas others achieved the desired size after only one injection. We next adjusted the protocol to first administer $2 \mathrm{mg} / \mathrm{kg}$ and then re-measure the glans in 1 month, proceeding to surgery if it was at least $15 \mathrm{~mm}$ or increasing injection to $4 \mathrm{mg} / \mathrm{kg}$ if it was not. The glans was measured again in a month, with continued monthly dose escalations to 8 and $16 \mathrm{mg} / \mathrm{kg}$ - to a maximum of $32 \mathrm{mg} / \mathrm{kg}$ given to a single patient to achieve a glans size of $15 \mathrm{~mm}$. This varying testosterone stimulation needed to grow the glans was considered evidence of partial androgen resistance found in patients with proximal hypospadias [13].

Although the endpoint for testosterone injection was a specific glans size, the goal of therapy was to reduce UCs, including glans dehiscence. We compared UCs in patients who required stimulation to reach glans width of at least $15 \mathrm{~mm}$ with those with similar hypospadias severity whose glans was naturally this size, and we found that complications remained significantly greater in those pre-treated with testosterone [14]. Accordingly, we stopped using hormone injection.

There is only one other report concerning UCs following preoperative androgen stimulation. A small trial randomly assigned 75 boys with mostly distal hypospadias to 3 months of daily topical dihydrotestosterone gel versus no treatment, finding significantly fewer fistulas, glans dehiscences, and meatal stenoses in those treated [15]. Therefore, the role, if any, for preoperative hormone stimulation remains uncertain.

\section{Modified glansplasty}

When testosterone-induced growth of glans diameter failed to reduce dehiscence, we changed our glansplasty method. At the time we were analyzing our results, Warren Snodgrass happened to visit Japanese surgeons to observe their means of correcting proximal hypospadias and saw that their dissection of the glans before closing it over the neourethra was more extensive than his. They had earlier visited Dallas and subsequently began measuring glans width, reporting that the mean was $12.5 \mathrm{~mm}$ yet glans dehiscence occurred in less than $1 \%$ of patients (Tanakazi YK, personal communication, 2012).

We adopted their technique in 2012, dissecting the glans wings not only laterally but also distally off the corpora cavernosa to effectively lengthen the wings and reduce tension on their subsequent approximation. Recent data analysis demonstrates that UCs have significantly decreased, halving the rate of glans dehiscence (Snodgrass W, unpublished data, 2014). Accordingly, we now perform this "extended" glans dissection when the diameter is less than $14 \mathrm{~mm}$, during reoperations for prior dehiscence, or when there is subjective tension on the closure for glans of $\leq 14 \mathrm{~mm}$. At a time when universities are increasingly questioning the cost/benefit ratio of professional travel, this example shows the potential learning that can occur only by surgeons observing each other working.

\section{Urethroplasty}

The first distal TIP article reported urethral plate tubularization by using interrupted 7-0 chromic catgut sutures that Warren Snodgrass placed through the epithelium [3]. He later changed to two-layer subepithelial suturing with 7-0 polyglactin, in part because chromic was not available in most other countries. However, subsequent analysis found no difference in UCs in patients on the basis of sutures and suturing methods used for distal repairs [16]. A subsequent randomized controlled trial (RCT) compared TIP urethroplasty using continuous versus interrupted polyglactin sutures and similarly reported no differences in UCs [17].

In contrast, Warren Snodgrass first tubularized proximal neourethras with one-layer continuous epithelial 7-0 chromic catgut suture, which resulted in a $25 \%$ fistula rate despite coverage with a dartos barrier flap. Faced with this outcome, he changed to two-layer subepithelial closure using interrupted 7-0 polyglactin and continuous 7-0 polydiaxanone, covering the neourethra with both corpus spongiosum and dartos. The fistula rate decreased to $12 \%$. Then he stopped using dartos and instead routinely covered the neourethra with tunica vaginalis, and the last published series of patients had no fistulas [18]. A retrospective review analyzed preputial flap repair for proximal hypospadias tubularizing the neourethra in either one or two layers and also reported a significant reduction in fistulas in those with two-layer urethro-plasty [19]. 
Few studies have examined the potential influence of suture types on UCs. One RCT compared polyglytone (rapid absorbing) to polydiaxanone (slow absorbing) in a total of 100 distal TIP repairs and found no difference in outcomes [20]. We reported no differences based on chromic catgut versus polyglactin for either urethroplasty or glansplasty in distal repairs $[8,16]$.

\section{Duration of follow-up}

A retrospective chart review of 26 patients evaluated for fistulas over the course of a 10-year period stated that $60 \%$ were apparent within 1 month of surgery but that nearly $25 \%$ were diagnosed more than 2 years after repair. The follow-up needed to capture $99 \%$ of fistulas would have been 20 years [21]. The mean follow-up in these boys was 6 months, and it is not known when later fistulas might have been encountered had they continued with routine periodic assessment rather than returning after being dismissed from follow-up.

Despite calls to review hypospadias patients into puberty, it is difficult-even in those countries with universal health care-to obtain such assessments, as evidenced by the lack of a single report describing systematic periodic follow-up after repair in infancy to the completion of puberty. While adult evaluations are needed to understand the functional outcomes of childhood surgery, the duration of time needed to determine most UC risk is much less.

We reported that $64 \%$ of UCs were diagnosed at the first postoperative visit, which in some patients was later than the 6 weeks that we recommended, and $81 \%$ were apparent within the first year after repair. The median times to diagnose were 2 months for glans dehiscence and 6 months for fistulas, meatal stenoses/urethral strictures, and diverticula, and we calculated that 14 boys would need indefinite follow-up after 1 year for each UC diagnosed later. However, our series was limited by the fact that follow-up was only a mean of 1 year in those without UC [22].

A recent retrospective review of 74 patients with primary distal TIP had a mean follow-up of 56 months, which to the best of our knowledge is the longest reported to date [23]. A total of six UCs occurred, and two fistulas and three meatal stenoses were diagnosed at more than two years following surgery. However, the authors did not state the duration or frequency of routine postoperative care, and $20 \%$ of their patients had follow-up for an average of only 13 months.

\section{Determining outcomes} Standardized photographs

Whereas UC rates are a somewhat objective assessment of outcomes, appearance and urinary function most often are subjectively determined by the surgeon. One study used standardized postoperative photographs judged with a 4-point scale for appearance of the glans, meatus, penile shaft, and overall cosmesis by a blinded panel composed of male and female surgeons and nurses. TIP, compared with Mathieu and onlay preputial flap repairs, had significantly better scores [24] (Figure 6).

Another photograph-based outcome instrument was recently described [25]. The hypospadias objective penile evaluation (HOPE) score was derived from meatal location and shape, glans shape, penile skin, and penile torsion or persistent ventral curvature. It was tested by 13 pediatric urologists and found to have both good interand intra-observer reliability ( 0.79 and 0.82 , respectively). This instrument is being used to analyze outcomes in a Dutch national multicenter registry for hypospadias repair.

\section{Questionnaires}

A penile perception score (PPS) instrument was validated to objectively assess impressions of genital appearance by patients, parents, and the surgeon after the operation. This tool also uses a 4-point scale to grade penile length, meatal location and shape, glans shape, straightness of erection, and overall cosmetic results [26].

The PPS was used to compare outcomes between four surgical techniques to repair proximal hypospadias: TIP versus onlay preputial flap when the urethral plate was conserved and modified onlay versus two-stage grafts when the urethral plate was transected. During followup, a mean of 4.5 years UC occurred in $23 \%$ without differences between these techniques. PPS scores were also similar, except that penile length was perceived as longer by parents of those boys who had two-stage repairs [27]. We recently began using a questionnaire administered both pre- and post-operatively that seeks to capture not only these cosmetic elements but also parent or patient perception of body image and social functioning as well as urinary function via a modified international prostate symptom score (I-PSS).

\section{Uroflowometry}

Uroflowometry is another objective tool, potentially useful to assess urinary function. A recent publication reported that flow rates $\left(\mathrm{Q}_{\max }\right.$ and $\left.\mathrm{Q}_{\text {ave }}\right)$ were similarly distributed in normal boys between the ages of 5 and 10 years and in those 11 to 15 years, with a significant change in mean $\mathrm{Q}_{\max }$ from $15 \pm 5$ to $22.5 \pm 7 \mathrm{cc} / \mathrm{sec}$ and in mean $\mathrm{Q}_{\text {ave }}$ from $8 \pm 3$ to $11 \pm 4 \mathrm{cc} / \mathrm{sec}$, in the younger versus the older age groups, respectively [28].

Uroflow tests in patients after TIP repair report increases in $\mathrm{Q}_{\max }$ over time. For example, one study reported that 


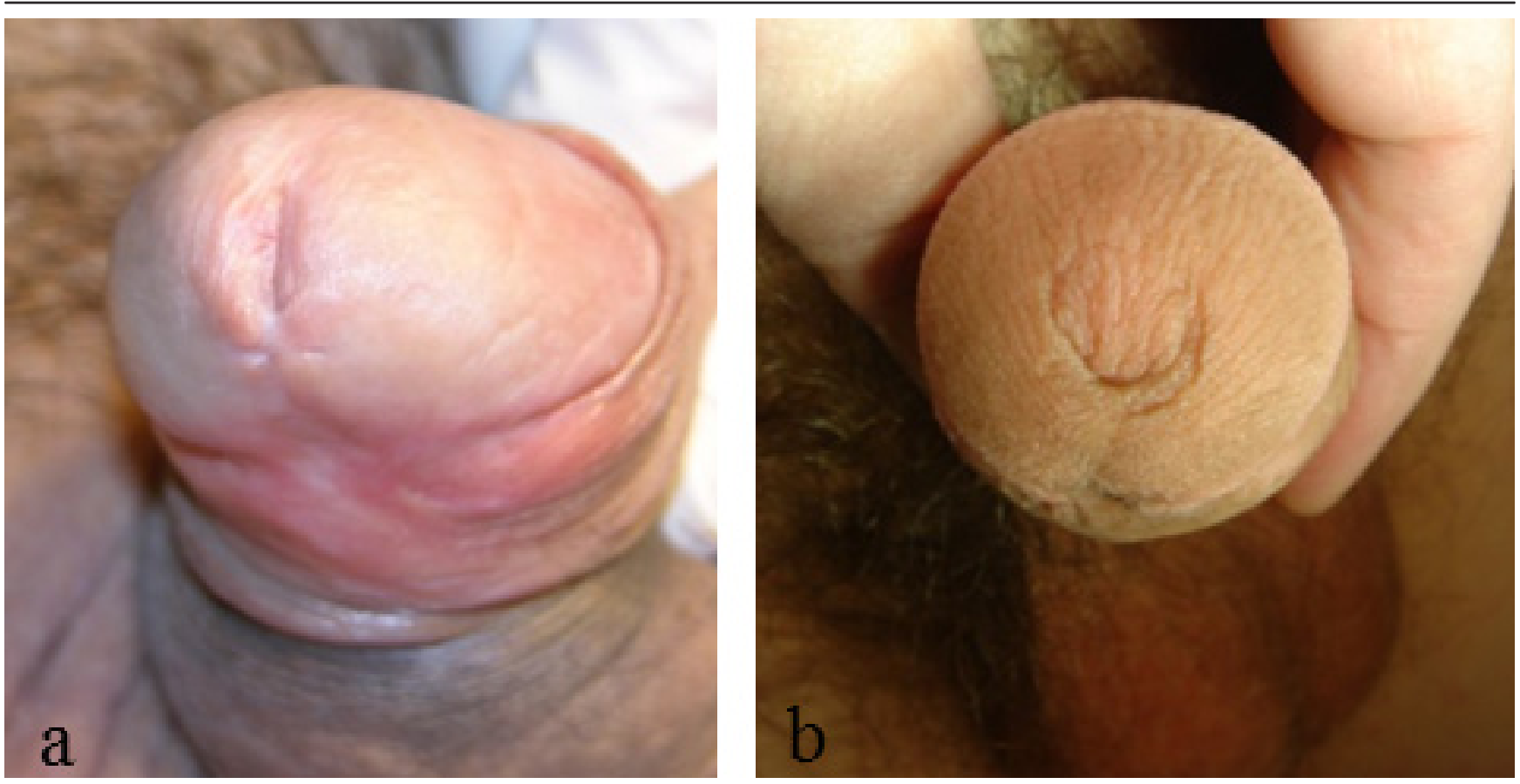

(a) Following tubularized incised plate urethroplasty, with a vertical slit meatus resembling normal. (b) Following Mathieu, with an abnormal, rounded meatus.

median $\mathrm{Q}_{\max } 2$ months after distal TIP was $9 \mathrm{cc} / \mathrm{sec}$, which increased significantly to $11 \mathrm{cc} / \mathrm{sec}$ by 1 year. Similar findings occurred after proximal TIP, changing from 6 to $8 \mathrm{cc} / \mathrm{sec}$ [29]. This likely reflected decreasing tissue stiffness during recovery from surgery. Continued improvement was documented with further follow-up. At 7 years after surgery, mean $Q_{\max }$ was $19 \mathrm{cc} / \mathrm{min}[30]$. Given that mean age at surgery was 4 years, the improvement in $\mathrm{Q}_{\max }$ may have related to the same increase that Gupta and colleagues [28] found on the basis of age of more than 10 years in boys without hypospadias.

We suspect that this increase in flow rates reflects increasing urethral diameter during puberty, although these authors did not report Tanner stages. From 14 patients, we have postoperative uroflow data obtained before and during puberty (average ages of 9 versus 13 years and Tanner stage 1 versus $\geq 2$ ), which also show significantly increased mean $\mathrm{Q}_{\max }(9$ to $17 \mathrm{cc} / \mathrm{sec}$ ) and $\mathrm{Q}_{\text {ave }}$ (6 to $\left.11 \mathrm{cc} / \mathrm{sec}\right)$ [31]. These observations suggest that the tubularized urethral plate is healthy and responds to pubertal growth similarly to normal urethras.

Uroflowometry has also been used recently to compare techniques. Results were similar during long-term follow-up between TIP, Mathieu, and MAGPI repairs for distal hypospadias [32]. We compared outcomes in prepubertal boys with a mean age of 8 years following primary distal TIP, proximal TIP, and two-stage grafts, finding that $\mathrm{Q}_{\max }$ and $\mathrm{Q}_{\mathrm{ave}}$ were the same. These results challenged the presumptions that longer neourethras necessarily cause decreased flow rates and that grafts might form a more elastic neourethra than a tubularized urethral plate [33].

\section{Adult outcomes}

To the best of our knowledge, all adult outcomes to date are reported after childhood urethroplasty using skin flaps, which are used much less commonly today. A systematic literature review pooled data from 20 articles concerning patients more than 14 years of age who had hypospadias repair at less than 6 years of age. Briefly summarized, approximately a third reported obstructive voiding symptoms, spraying, or a deviated stream, and $\mathrm{Q}_{\max }$ was significantly less than in controls. Twenty-five percent of patients also report having to milk their ejaculate from the neourethra [34]. These findings indicate that the neourethra is not a normal urethra.

Similar data are not yet available regarding TIP or twostage graft repairs that we use exclusively and that have rapidly become mainstays for repair worldwide. Most of our adult patients had reoperations using oral mucosa 
grafts and routinely report-if asked-that they dribble some additional urine after voiding and have to milk their ejaculate.

There has been speculation that pubertal growth can result in new UC or penile curvature after childhood hypospadias repair. We have not observed that, but rather it appears that problems that may have been brushed aside earlier by either the surgeon or parents become more obvious at puberty and demand attention.

\section{Improving the future}

Our experience making technical changes in proximal TIP urethroplasty and in glansplasty for the small glans demonstrates the value in collecting and reviewing accurate data. We have similar experiences in hypospadias reoperations that have also been published [33]. Consequently, we recommend that others similarly establish databases for personal quality improvement, which potentially can be accomplished by using the electronic medical record.

The Dutch have recently established a national multicenter registry for hypospadias outcomes with the goal of providing individual surgeons and centers with report cards. Their first review found wide variation in UCs, and several surgeons had a higher prevalence than expected from published results. Their next step is to explore methods to bring all participants into a similar range of outcomes (Van der Toorn F, personal communication, 2014). There are also plans to expand their registry to other European countries.

A similar model in the US likely would reduce variations in practices currently observed in various centers and potentially establish collaboration between centers to define best practices following the example of pediatric cancer treatments.

Surgeons are highly motivated to improve their practices-when shown reliable outcomes data. To better understand and compare results, UCs must be uniformly defined, duration of follow-up standardized, and objective postoperative assessments such as HOPE or PPS used routinely.

As we stated earlier, surgeons also benefit from observing each other performing these operations. Live surgery courses transmitted by webinar are one means to demonstrate different repairs while allowing observers to interact with the surgeons. We plan to expand this concept to include private webinars connecting surgeons for interactions as we repair challenging problems in patients they referred for our care. We also plan to offer intensive 1- to 3-day courses demonstrating repair of cases a surgeon is finding difficult, operating either in Dallas or with a visit to that surgeon's hospital.

In addition, our specialty must admit that although hypospadias is the second most common birth defect in boys, it remains an uncommon condition. To date, no study has determined minimum annual volumes to achieve and maintain competency, but self-reported operative logs to the American Board of Urology from full-time pediatric urologists suggest the need for such data, given that the median number of distal repairs per year was 12, and for proximal repairs, only 2 [35]. Since both proximal repairs and reoperations have increased complication rates, we recommend that centers designate a single surgeon or surgical team to perform them.

Finally, if UC rates do not vary significantly between various surgical techniques, then surgeons must use cosmetic outcomes and patient-reported functional outcomes (urinary spraying for example) to determine the best repairs. For some, that will mean abandoning operations learned from mentors. For all surgeons it means acquiring greater objective knowledge of the operations we perform with the goal of improving them for our patients.

\section{Application to other surgeries}

The same processes we describe to improve our hypospadias operations potentially apply to other surgeries. First, surgeons need to know their own outcomes for the operations they perform, and these outcomes are best determined by using prospective data collection so they can track technical changes and the improvements that occur.

Those surgeons who discover that their results are below expectations may benefit from observing others with proven better outcomes. A recent study found that surgeons could rate the technical skills of other surgeons by watching video clips of their operations and that these ratings correlated with outcomes. In other words, those surgeons thought to demonstrate poor technique had two times the complications as those with good technique [36]. The authors speculated that those rated poor might improve with coaching, which they are now studying by using anonymous feedback from peers.

It is also recognized that complex operations are better mastered by surgeons performing greater numbers of those cases [37]. Proximal hypospadias repair is an uncommon and technically demanding operation that should be subspecialized into fewer hands, and there are such procedures in all surgical fields. 
Finally, reliance on operations with the best outcomes should replace continued use of procedures a surgeon may have learned from a mentor years ago-which he or she is "comfortable" doing-that give poorer results. A surgeon recently commented "you dance with the one who brought you" to explain why he persisted in using an operation despite evidence that others gave better outcomes. Perhaps more patient-derived outcomes data, tabulating the results that matter to those undergoing operations, will help change such attitudes.

\section{Abbreviations \\ HOPE, hypospadias objective penile evaluation; MAGPI, meatal advancement and glanduloplasty; PPS, penile perception score; $\mathrm{Q}_{\mathrm{ave}}$, average flow rate; $\mathrm{Q}_{\max }$ max- imum flow rate; RCT, randomized controlled trial; TIP, tubularized incised plate urethroplasty; UC, urethro- plasty complication.}

\section{Disclosures}

The authors declare that they have no disclosures.

\section{References}

I. Snodgrass W, Prieto J: Straightening ventral curvature while preserving the urethral plate in proximal hypospadias repair. j Urol 2009, 182:1720-5.

2. Duckett JW, Snyder HM, 3rd: Meatal advancement and glanuloplasty hypospadias repair after 1,000 cases: avoidance of meatal stenosis and regression. J Urol 1992, 147:665-9.

3. Snodgrass W: Tubularized, incised plate urethroplasty for distal hypospadias. J Urol 1994, I 5 I:464-5.

4. Bush NC, Holzer M, Zhang S, Snodgrass W: Age does not impact risk for urethroplasty complications after tubularized incised plate repair of hypospadias in prepubertal boys. J Pediatr Urol 2012, 9:252-6.

\section{FIOOOPrime}

\section{RECOMMENDED}

5. Bush N, Villanueva C, Snodgrass W: Glans size is an independent risk factor for urethroplasty complications after hypospadias repair [abstract]. Presented at the 6Ist Annual Meeting of the Society for Pediatric Urology: 3-5 May 2013; San Diego, CA.

6. Snodgrass $\mathrm{W}$, Villanueva $\mathrm{C}$, Bush $\mathrm{N}$ : Primary and reoperative hypospadias repair in adults: are results different than in children? J Urol 2014, S0022-5347:03959-7.

7. Snodgrass W, Grimsby G, Bush N: Coronal fistula repair under the glans without reoperative hypospadias glansplasty or urinary diversion [abstract]. Presented at the 62nd Annual Meeting of the Society for Pediatric Urology: 16-18 May 2014; Orlando, FL.

8. Snodgrass W, Cost N, Nakonezny PA, Bush N: Analysis of risk factors for glans dehiscence after tubularized incised plate hypospadias repair. J Urol 20II, 185:1845-9.

9. Bush NC, Dajusta D, Snodgrass WT: Glans penis width in patients with hypospadias compared to healthy controls. J Pediatr Urol 20|3, 9: ||88-9|.

10. Luo CC, Lin JN, Chiu CH, Lo FS: Use of parenteral testosterone prior to hypospadias surgery. Pediatr Surg Int 2003, 19:82-4.

II. Nerli RB, Koura A, Prabha V, Reddy M: Comparison of topical versus parenteral testosterone in children with microphallic hypospadias. Pediatr Surg Int 2009, 25:57-9.
12. Gearhart JP, Jeffs RD: The use of parenteral testosterone therapy in genital reconstructive surgery. J Urol 1987, 138: 1077-8.

13. Snodgrass WT, Villanueva C, Granberg C, Bush NC: Objective use of testosterone reveals androgen insensitivity in patients with proximal hypospadias. J Pediatr Urol 2013, 10:118-22.

14. Bush N, Keays M, Villanueva C, Snodgrass W: Preoperative testosterone injection does not decrease hypospadias urethroplasty complications [abstract]. Presented at the 25th Anniversary Congress of the European Society for Paediatric Urology: 7-I0 May 2014; Innsbruck, Austria.

15. Kaya C, Bektic J, Radmayr C, Schwentner C, Bartsch G, Oswald J: The efficacy of dihydrotestosterone transdermal gel before primary hypospadias surgery: a prospective, controlled, randomized study. J Urol 2008, I79:684-8.

FlOOOPrime

RECOMMENDED

16. Snodgrass WT, Bush N, Cost N: Tubularized incised plate hypospadias repair for distal hypospadias. J Pediatr Urol 2010 , 6:408-13

17. Sarhan O, Saad M, Helmy T, Hafez A: Effect of suturing technique and urethral plate characteristics on complication rate following hypospadias repair: a prospective randomized study. J Urol 2009, 182:682-5; discussion 5-6.

\section{FlOOOPrime
RECOMMENDED}

18. Snodgrass $W$, Bush N: Tubularized incised plate proximal hypospadias repair: Continued evolution and extended applications. J Pediatr Urol 201 I, 7:2-9.

19. Chuang JH, Shieh CS: Two-layer versus one-layer closure in transverse island flap repair of posterior hypospadias. J Pediatr Surg 1995, 30:739-42.

\section{FlOOOPrime}

\section{RECOMMENDED}

20. Guarino N, Vallasciani SA, Marrocco G: A new suture material for hypospadias surgery: a comparative study. J Urol 2009, | 81:|3|8-22; discussion 22-3.

\section{FlOOOPrime}

\section{RECOMMENDED}

21. Wood HM, Kay R, Angermeier KW, Ross JH: Timing of the presentation of urethrocutaneous fistulas after hypospadias repair in pediatric patients. J Urol 2008, 180:1753-6.

\section{FlOOOPrime}

\section{RECOMMENDED}

22. Snodgrass W, Villanueva C, Bush NC: Duration of follow-up to diagnose hypospadias urethroplasty complications. J Pediatr Urol 20l4, 10:208-II.

23. Aslam R, Campbell K, Wharton S, Bracka A: Medium to long term results following single stage Snodgrass hypospadias repair. J Plast Reconstr Aesthet Surg 2013, 66:1591-5.

\section{FlOOOPrime}

\section{RECOMMENDED}

24. Ververidis M, Dickson AP, Gough DC: An objective assessment of the results of hypospadias surgery. BJU Int 2005, 96: I35-9.

\section{FlOOOPrime}

\section{RECOMMENDED}

25. van der Toorn F, de Jong TP, de Gier RP, Callewaert PR, van der Horst EH, Steffens MG, Hoebeke P, Nijman RJ, Bush NC, Wolffenbuttel KP, van den Heijkant MM, van Capelle JW, Wildhagen M, Timman R, van Busschbach J]: Introducing the HOPE (Hypospadias Objective Penile Evaluation)-score: A validation study of an objective scoring system for evaluating cosmetic appearance in hypospadias patients. J Pediatr Urol 2013, 9:1006-16.

26. Weber DM, Schonbucher VB, Landolt MA, Gobet R: The Pediatric Penile Perception Score: an instrument for 
patient self-assessment and surgeon evaluation after hypospadias repair. J Urol 2008, 180:1080-4; discussion 4.

\section{FlOOOPrime}

27. Castagnetti M, Zhapa E, Rigamonti W: Primary severe hypospadias: comparison of reoperation rates and parental perception of urinary symptoms and cosmetic outcomes among 4 repairs. J Urol 2013, I89:1508-13.

\section{FlOOOPrime \\ RECOMMENDED}

28. Gupta DK, Sankhwar SN, Goel A: Uroflowmetry nomograms for healthy children 5 to 15 years old. J Urol 2013, 190:1008-13.

\section{FlOOOPrime \\ RECOMMENDED}

29. Holmdahl G, Karstrom L, Abrahamsson K, Doroszkiewicz M, Sillen U: Hypospadias repair with tubularized incised plate. Is uroflowmetry necessary postoperatively? J Pediatr Urol 2006, 2:304-7.

\section{FlOOOPrime} RECOMMENDED

30. Andersson M, Doroszkiewicz M, Arfwidsson C, Abrahamsson K, Holmdahl G: Hypospadias repair with tubularized incised plate: Does the obstructive flow pattern resolve spontaneously? J Pediatr Urol 20II, 7:44I-5.

\section{FlOOOPrime RECOMMENDED}

31. Snodgrass W, Grimsby G, Bush N: Urinary flow rates after hypospadias repair increase during puberty [abstract]. Presented at the Pediatric Urology Fall Congress: 24-26 October 20I4; Miami, FL.
32. Hueber PA, Houle AM, Franc-Guimond J, Barrieras D: Long-term urinary function after Snodgrass distal hypospadias repair: a single center retrospective comparative analysis with Mathieu and MAGPI repair [abstract]. Presented at the 25th Anniversary Congress of the European Society for Paediatric Urology: 7-10 May 2014; Innsbruck, Austria.

33. Snodgrass W, Grimsby G, Bush N: Uroflow results before and after hypospadias repair in toilet trained boys [abstract]. Presented at the Pediatric Urology Fall Congress: 24-26 October 2014; Miami, FL.

34. Rynja SP, de Jong TP, Bosch JL, de Kort LM: Functional, cosmetic and psychosexual results in adult men who underwent hypospadias correction in childhood. I Pediatr Urol 201I, 7:504-15.

\section{FlOOOPrime}

\section{RECOMMENDED}

35. Kogan BA, Feustel PJ: What can we learn from pediatric urology certification logs? Urology 201 I, 78:147-52.

\section{FlOOOPrime}

\section{RECOMMENDED}

36. Birkmeyer JD, Finks JF, O'Reilly A, Oerline M, Carlin AM, Nunn AR, Dimick J, Banerjee M, Birkmeyer NJ: Michigan Bariatric Surgery Collaborative Surgical skill and complication rates after bariatric surgery. N Engl J Med 20I3, 369:1434-42.

\section{FlOOOPRime
RECOMMENDED}

37. Birkmeyer JD, Stukel TA, Siewers AE, Goodney PP, Wennberg DE, Lucas FL: Surgeon volume and operative mortality in the United States. N Engl J Med 2003, 349:2I I7-27. 